\title{
An exploration of the factors that influence employee participation in Europe
}

\author{
Elizabeth F. Cabrera ${ }^{\mathrm{a}, *}$, Jaime Ortega ${ }^{\mathrm{a}, 1}$, Ángel Cabrera ${ }^{\mathrm{b}, 2}$ \\ ${ }^{a}$ Departamento de Economía de la Empresa, Universidad Carlos III de Madrid, \\ c/Madrid 126, 28903 Getafe (Madrid), Spain \\ ${ }^{\mathrm{b}}$ Instituto de Empresa, María de Molina 12, 28006 Madrid, Spain
}

\begin{abstract}
The goal of this study was to identify the determinants of direct employee participation in organizations across Europe. Some factors were predicted to be related to levels of participation in general, namely, competition, sector, the pursuit of a differentiation strategy based on either quality or service, and indirect participation. Two additional factors were expected to be differentially related to two forms of direct participation: consultation and delegation. These factors were organizational size and the pursuit of a cost leadership business strategy. The hypothesized relationships were contrasted using data from the EPOC survey, a representative survey of over 5,700 organizations located in 10 European Union countries. The results supported 11 of the 14 predicted relationships.
\end{abstract}

Keywords: Employee participation; Employee involvement; Delegation; Consultation

\section{Introduction}

A currently popular approach to Human Resource Management involves the use of "high performance work systems" (Huselid, 1995; Jackson \& Schuler, 1995; Pfeffer, 1994). Studies have shown a positive relationship between these systems and a variety of indicators of firm performance. One of the HR prac tices that is often included in the description of high performance work systems is that of employee invol

\footnotetext{
* Corresponding author. Tel: +34-91-624-9709; Fax: +34-91-624-9607.

E-mail addresses: beth@emp.uc3m.es (E.F. Cabrera), jortega@emp.uc3m.es (J. Ortega), angel.cabrera@ie.edu (Á. Cabrera).

${ }^{1}$ Tel: +34-91-624-9612; Fax: +34-91-624-9607.

${ }^{2}$ Tel: +34-91-568-9600; Fax: +34-91-745-2147.
}

vement or participation. There is a growing consensus among HR researchers and professionals that partici pative management can enhance employee motiva tion, commitment, productivity and job satisfaction (Cotton, 1993). While there is a great deal written about the potentially positive effects of employee involvement, there is less known about the factors that determine the amount and/or type of participation that organizations adopt.

In this paper, we propose a number of hypotheses regarding the determinants of level of employee invol vement across organizations. The factors expected to affect general levels of participation include competi tion, sector, the pursuit of a differentiation strategy based on either quality or service, and indirect parti cipation. We further hypothesize that two factors influence the differential adoption of consultative 
vs. delegative participation. Specifically, organiza tional size and the pursuit of a cost leadership business strategy are expected to be differentially related to the two forms of direct participation.

Most of the hypotheses are based on the theoretical arguments proposed by two different models of parti cipation: affective and cognitive models. The hypoth eses are contrasted using data collected from 10 European countries in a very comprehensive survey called "Employee Direct Participation in Organisa tional Change" (EPOC, 1997). Conclusions are drawn regarding the factors found to affect level and type of direct employee participation and the direction of these influences.

\section{Employee participation}

The importance of employee participation as a busi ness strategy was first stressed in the late 1920s and early 1930s. The Hawthorne studies (Mayo, 1933) gave rise to an increasing interest in the human determinants of productivity. The "human relations" approach to management emphasized the importance of commu nication between employees and their superiors. The lack of strong empirical support for these theories, however, turned initial enthusiasm into mild skepticism (Anthony, Perrewe, \& Kacmar, 1993). More recently management practice has kindled a renewed interest in this issue. This is due to growing evidence that employee participation increases effort, which subse quently improves efficiency and productivity, it reduces the cost of monitoring employees and it leads to increased commitment (Doucouliagos, 1995).

Employee participation can take the form of a variety of management practices such as, for example, participative management, employee involvement programs, empowerment or workplace democracy. Each of these practices attempts in some way to involve employees in the sharing of information and/or making of decisions. Participation may be direct or indirect. Direct participation involves the employees themselves, whereas indirect participation takes place through an intermediary of employee representative bodies, such as works councils or trade unions (EPOC, 1997).

Two main forms of direct participation include consultative participation and delegative participation
(Geary \& Sisson, 1994). Consultative participation refers to practices where management encourages employees to share their opinions regarding work related concerns, yet retains the right to make all final decisions. Examples of consultative participation include regular meetings with supervisors, attitude surveys and employee suggestion plans. Delegative participation, on the other hand, gives employees increased responsibility and autonomy to organize and perform their jobs as they see fit. Participation in the scheduling of work, improving work processes and attendance and absence control are examples of delegative participation where employees participate directly in work decisions (Cotton, Vollrath, Froggatt, Lengnick Hall, \& Jennings, 1988).

Two theoretical models address the potential advan tages of direct employee participation. According to cognitive models of participative effects (Anthony, 1978; Frost, Wakely, \& Ruh, 1974; Miller \& Monge, 1986), employee involvement increases the flow of information in organizations. Often employees per forming seemingly unimportant tasks have access to valuable information. Higher level managers are more likely to gain access to this information through participative management practices. Therefore, prac tices that encourage employees to more freely share information lead to higher levels of performance (Lawler, Mohrman, \& Ledford, 1995).

Affective models of participative effects (Blake \& Mouton, 1964; Likert, 1967) originated with the aforementioned 'human relations' school of manage ment. They propose that employee involvement fulfils higher order needs which leads to greater satisfaction. Higher levels of satisfaction in turn strengthen moti vation, which has a positive effect on productivity (Miller \& Monge, 1986). Thus, cognitive models propose that employee participation affects produc tivity directly by increasing the flow of information in organizations, while affective models propose that employee participation has a direct effect on employee satisfaction, which may in turn increase productivity.

\section{Determinants of employee participation}

There has been a considerable amount of research regarding employee participation. Most of the studies have focused on the outcomes of participative man 
agement. Evidence of this comes from the number of meta analyses that have been conducted in order to summarize the findings of participation's effects on outcomes such as satisfaction and performance (Dou couliagos, 1995; Miller \& Monge, 1986; Wagner, 1994). In general, the results suggest that employee involvement has a small yet consistent effect on satisfaction and performance (Wagner, 1994). Despite this plethora of studies, there is little known as to which factors determine the level of employee invol vement that an organization will likely adopt. The goal of this study is to do just that: to explore the determi nants rather than the effects of the adoption of employee participation practices.

In identifying these factors, we have divided them into two groups; those expected to affect levels of employee participation in general and those expected to differentially affect the use of two types of employee participation. Specifically, we hypothesize that amount of competition, sector, the pursuit of a differentiation strategy based on either quality or service, and amount of indirect participation will influence general levels of employee involvement. We further propose that organizational size and the pursuit of a business strategy based on cost leadership will have different effects on consultative vs. delega tive participation.

Below we describe in more detail the predicted relationships and propose a number of hypotheses, presenting first those related to levels of participation in general, followed by those expected to affect the form of participation chosen.

\subsection{Competition}

The increasingly competitive environment faced by organizations has caused them to re evaluate their structures and employee relations. This has been one of the main influences on the rise of participative management (Hyman \& Mason, 1995). Lawler et al. (1995) reported that foreign competition, rapidly grow ing markets and extreme performance pressures are all strongly related to the adoption of employee involve ment practices. Clearly companies that operate in highly competitive environments must maximize their productivity and recent meta analyses have shown that employee participation is positively related to produc tivity (Doucouliagos, 1995; Miller \& Monge, 1986).
Organizations that depend on the productivity of their employees to survive fierce competition should be interested in both direct and indirect ways of increasing employee productivity. That is, both the cognitive and affective models of employee participa tion apply to this situation. Given that employee satisfaction and productivity should be of utmost concern for organizations facing competitive environ ments, we expect:

Hypothesis 1a: Consultative participation is posi tively related to the level of competition faced by an organization.

Hypothesis 1b: Delegative participation is positively related to the level of competition faced by an orga nization.

\subsection{Sector}

Heller, Pusic, Strauss, and Wilpert (1998) attribute the spread of participation in part to the growth of the service industry. They point out that service employ ees' attitudes, unlike those of manufacturing employ ees, are "an essential part of the 'product' they provide" (Heller et al., 1998: 12). Thus, based upon the premise of the affective models of participation, that participation is positively related to satisfaction, one would expect higher levels of participation to lead to better service quality. A number of companies have, in fact, discovered that employee satisfaction is related to customer satisfaction (Bowen \& Lawler, 1995; Schneider \& Bowen, 1995). Hyman and Mason (1995: 44) observed that managers in the service sector, in contrast to the manufacturing sector, must "gain more than mere compliance from their subor dinates." Thus, there seems to be agreement that the motivational impact of employee involvement is more important for success in the service sector than in the manufacturing sector. Accordingly, we expect:

Hypothesis 2a: Consultative participation will be greater in the service sector than in the manufacturing sector.

Hypothesis 2b: Delegative participation will be greater in the service sector than in the manufacturing sector. 


\subsection{Differentiation strategy}

Organizations that choose to compete based on a strategy of differentiation focus on creating a product or service that is unique (Porter, 1980). These orga nizations may choose to be unique in a variety of ways. Two typical differentiation strategies are those of product quality and customer service.

Most quality improvement programs are based upon the premise that increased sharing of information among employees has a positive impact on product reliability and quality (Beatty, 1991; Deming, 1986; Lawler et al., 1995). In accordance with the cognitive models of participation, employee involvement increases the sharing of information, which improves the quality of decision making. Given that both con sultative and delegative participation should positively affect information sharing, we predict:

Hypothesis 3a: Consultative participation is posi tively related to the pursuit of a differentiation strategy based on quality.

Hypothesis 3b: Delegative participation is positively related to the pursuit of a differentiation strategy based on quality.

Employee participation is also important for custo mer service. Increased information sharing should lead to better planning and problem solving which improve service delivery efficiencies. Customer satisfaction is further increased when employees are given the free dom to respond directly to their needs. Moreover, as previously mentioned, a positive relationship has been found between employee satisfaction and customer satisfaction and between participative management and employee satisfaction. Thus, both the affective and the cognitive models of participation would suggest that employee involvement be used in order to improve customer service. Hence we propose the following:

Hypothesis 4a: Consultative participation is posi tively related to the pursuit of a differentiation strategy based on service.

Hypothesis 4b: Delegative participation is positively related to the pursuit of a differentiation strategy based on service.

\subsection{Indirect participation}

Different countries have their own particular form of industrial relations as a result of their unique political and social history. In reflecting on participation in Europe, Knudsen (1995) states that trade unionism is clearly a common dynamic that influences employee participation in all European countries in general. However, he concludes that on a more concrete level of analysis, there are more differences between national systems of employee participation than there are similarities. In some countries participation is based on statutory regulation, in others there is no regulation regarding employee participation, while in certain countries there is a mix of legal and voluntary regulation. In some countries works councils members are elected by trade union members, while in other countries all employees, irrespective of their trade union membership, elect works councils members.

Another major difference among national systems of labor relations are the powers granted to trade unions and to works councils. Some may have the power to call strikes and others may not; some can take legal action, others cannot; some can participate in decisions regarding training and compensation, others cannot. There is indeed a great deal of diversity in the nature of employee participation and the structure and operations of works councils among different coun tries. Markey and Monat (1998) warn that a global reference to a form of European works councils hides marked differences in their operations which often produce great variability in terms of actual employee participation.

These differences in national systems of labor relations will certainly affect levels of employee par ticipation among the European countries. However, it is important to note that most of these differences refer to differences in indirect participation. Knudsen (1995) points out that legal regulations on direct participation are rare. One of the only exceptions is the French law on "expression groups" which requires that companies with 50 employees or more organize regular meetings where employees can express their opinions regarding their work. Thus, while national systems influence to a great extent levels of indirect participation, most direct employee participation is determined by employer decisions, rather than by labor regulations. 
Whether regulated or not, it is likely that levels of indirect participation affect levels of direct participa tion. Hyman and Mason (1995) suggest that legisla tion can encourage employers to adopt greater levels of employee participation in general. Continuous government support of participation initiatives can instill the idea that employee participation is a "posi tive employment practice." It may also be the case that organizations that are legally obliged to adopt certain forms of indirect participation discover the advantages of employee participation and choose to adopt forms of direct participation as well. We, therefore, predict that levels of indirect participation, which we expect to be strongly influenced by national systems of labor regulation, will have a positive impact on levels of direct participation. Specifically, we predict:

Hypothesis 5a: Consultative participation is posi tively related to the amount of indirect participation.

Hypothesis 5b: Delegative participation is positively related to the amount of indirect participation.

In summary, we expect to find a positive relation ship between both forms of participation and level of competition. We further hypothesize that organiza tions in the service sector will have higher levels of both types of participation than those in the manu facturing sector. We predict that the pursuit of a differentiation strategy based on either quality or service will be positively related to both forms of participation. Finally, we expect that level of indirect participation will positively affect level of direct participation. We turn now to the two factors that we expect to differentially affect levels of delegative vs. consultative participation.

\subsection{Organizational size}

The effect of organizational size on levels of employee participation is unclear (Heller et al., 1998). The previously mentioned longitudinal survey of employee involvement found a significant positive relationship between organizational size and employee participation practices (Lawler et al., 1995). Likewise, the aggregate result of surveys con ducted in the U.K. between 1985 and 1991 showed a positive linear relationship between organizational size and number of involvement initiatives (Hyman \& Mason, 1995). This may be due to the fact that larger organizations are more likely to adopt innova tive practices and/or because they have greater moti vational problems that they try to resolve through participative management, as suggested by the affec tive models of participation.

Yet other studies have found a negative relationship between organizational size and levels of employee involvement (Heller et al., 1998). It may be that different relationships have been found because the direction of the relationship between organizational size and employee involvement depends on the type of participation employed.

As previously mentioned, large organizations may have motivational problems that consultative partici pation could help to solve. The affective models of participation would suggest that consultation be used to increase employee satisfaction. And in fact, one of the practices used significantly more in larger orga nizations according to Lawler et al. (1995) was survey feedback, a practice most often used to assess attitudes and climate. On the other hand, it may be more difficult to manage delegative participation in a large organization (Heller et al., 1998). Information sharing requires efficient communication and higher levels of trust. Smaller organizations tend to have more com mitted employees and open communications. The increased bureaucracy and impersonalization of larger organizations may make the actual delegation of decision making less likely. Hence we expect:

Hypothesis 6a: Consultative participation is posi tively related to organizational size.

Hypothesis 6b: Delegative participation is negatively related to organizational size.

\subsection{Cost leadership strategy}

As we have already explained, we expect that the goals pursued by organizations following a differen tiation strategy will lead them to have relatively high levels of both consultative and delegative participa tion. That is, we predict that a business strategy based on differentiation will positively affect the general level of participation that the organization adopts. On the other hand, we propose that organizations follow 
ing a cost leadership strategy will adopt different levels of consultative vs. delegative participation.

These organizations emphasize cost control and efficiency in order to be able to offer lower prices to their clients (Porter, 1980). An important factor in controlling costs is to minimize labor costs. Aghion and Tirole (1997) suggest that organizations employ participative management practices in hopes of redu cing employee demands for higher wages. That is, they share the point of view of the affective models of participation that participation increases employee satisfaction. They further believe that satisfied employees are less likely to request wage increases.

On the other hand, when employees are viewed as a "cost" they are treated as a factor of production. They tend to be closely monitored and are given little discretion in their jobs (Hyman \& Mason, 1995). Organizations that adhere to this view of management would consider the time required for involving employees, for sharing information and soliciting opinions as a cost. In accordance with such a philo sophy, delegation would be considered to be even more costly than consultation because more time is required for employees to reach a consensus when making decisions. We therefore expect to find:

Hypothesis 7a: Consultative participation is posi tively related to the pursuit of a cost leadership strategy.

Hypothesis 7b: Delegative participation is negatively related to the pursuit of a cost leadership strategy.

\section{Methodology}

\subsection{EPOC survey}

The EPOC survey was commissioned by the Eur opean Foundation for the Improvement of Living and Working Conditions. It was designed to determine the nature and extent of direct participation of employees in organizations across 10 European countries: Den mark, France, Germany, Ireland, Italy, The Nether lands, Portugal, Spain, Sweden, and the U.K. The number of organizations per country differed accord ing to population size, the number of employees in manufacturing and services, and average organiza
Table 1

Sample size and response rate by country

\begin{tabular}{lccc}
\hline Country & $\begin{array}{l}\text { Surveys sent } \\
\text { (minus 'return to sender') }\end{array}$ & $\begin{array}{l}\text { Surveys } \\
\text { returned }\end{array}$ & $\begin{array}{l}\text { Response } \\
\text { rate }(\%)\end{array}$ \\
\hline Denmark & 2,535 & 674 & 26.6 \\
France & 4,870 & 598 & 12.3 \\
Germany & 4,887 & 826 & 16.9 \\
Ireland & 984 & 382 & 38.8 \\
Italy & 3,849 & 499 & 13.0 \\
The Netherlands & 2,303 & 505 & 21.9 \\
Portugal & 996 & 298 & 29.9 \\
Spain & 4,872 & 460 & 9.4 \\
Sweden & 2,401 & 732 & 30.5 \\
United Kingdom & 4,881 & 812 & 16.6 \\
Total & 32,582 & 5,786 & 17.8 \\
\hline
\end{tabular}

Source: EPOC (1997).

tional size. Questionnaires were mailed to the general managers of 32,582 companies in June 1996. The final number of surveys returned was 5,786 for a response rate of $17.8 \%$. Table 1 shows the sample figures and Table 2 shows the distribution of organizational size across the 10 countries. The gross sample of organiza tions included companies from manufacturing and service sectors as shown in Table 3.

\subsection{Measures}

\subsubsection{Dependent variable}

The survey included 24 items pertaining to the practice of direct participation. Eight questions assessed the use of forms of consultative participation,

Table 2

Organizational sizes by country (percentages)

\begin{tabular}{lllll}
\hline \multirow{2}{*}{ Country } & \multicolumn{4}{l}{ Number of employees } \\
\cline { 2 - 5 } & $1-49$ & $50-199$ & $200-499$ & $500+$ \\
\hline Denmark & 59 & 31 & 5 & 5 \\
France & 16 & 65 & 14 & 5 \\
Germany & 21 & 58 & 14 & 7 \\
Ireland & 56 & 32 & 6 & 6 \\
Italy & 8 & 72 & 13 & 7 \\
The Netherlands & 64 & 30 & 3 & 3 \\
Portugal & 53 & 39 & 4 & 4 \\
Spain & 18 & 63 & 14 & 5 \\
Sweden & 59 & 36 & 3 & 2 \\
United Kingdom & 20 & 60 & 15 & 5 \\
\hline
\end{tabular}

Source: EPOC (1997). 
Table 3

Sector by country (percentages)

\begin{tabular}{lll}
\hline Country & \multicolumn{2}{l}{ Sector } \\
\cline { 2 - 3 } & Service & Manufacturing \\
\hline Denmark & 56 & 44 \\
France & 61 & 39 \\
Germany & 61 & 39 \\
Ireland & 65 & 35 \\
Italy & 31 & 69 \\
The Netherlands & 67 & 33 \\
Portugal & 57 & 43 \\
Spain & 53 & 47 \\
Sweden & 63 & 37 \\
United Kingdom & 65 & 35 \\
\hline
\end{tabular}

Source: EPOC (1997).

such as regular meetings with one's immediate man ager or attitude surveys. Sixteen questions assessed the use of delegative participation, such as having the right to make decisions regarding the improvement of work processes or how to deal with external clients. The eight items pertaining to consultative participation were aggregated to form a single measure of this type of participation (0 8), and the sixteen items assessing delegative participation were aggregated to form a single measure of this type of participation $\left(\begin{array}{ll}0 & 16\end{array}\right)$.

\subsubsection{Independent variables}

Competition was assessed with one item that asked managers to describe the level of competition for the products and/or services of their company on a 14 scale, ranging from no competition to both domestic and foreign competition. The survey asked respon dents to categorize their organization into 1 of 15 sectors. These 15 sectors were further categorized into either service or manufacturing sectors. Three items assessed the business strategies included in the hypotheses. Each item asked respondents to rate on a 13 scale the importance (not important to very important) of the strategy for their company's com petitive success. The first item assessed the impor tance of quality, the second the importance of service, and the third the importance of price. Indirect parti cipation was assessed by a composite score made up of three items. The first item asked whether or not trade union representatives were recognized by the organi zation for consultation and or joint decision making purposes. The second and third items asked the same of representatives elected to works councils and repre sentatives to an advisory committee. The natural logarithm of number of employees was used to test for the effects of organizational size.

\subsubsection{Control variables}

Three variables were included as control variables: country, private vs. public status, and percent of employees who are union members. Given the influ ence of culture on organizational practices (Boyaci giller \& Adler, 1991; Child, 1981), it is likely that different countries have different levels of direct par ticipation in general. It is also likely that private companies, which often face stronger competition, use more direct participation than public companies. This variable was measured with one item that asked managers to categorize their company as public or private. Finally, trade unions represent employees' interests to management. Given that the affective models of participative effects predict that employee participation satisfies higher order needs, it is likely that participative management be an important issue to union members. Trade union membership was assessed by one item that asked for the proportion of union members among employees in the largest occupational group.

\section{Results}

Table 4 reports the means, standard deviations and correlations among all the study variables. In order to test the predicted relationships, two linear regression analyses were performed. In the first analysis con sultative participation was entered as the dependent variable and in the second analysis delegative parti cipation served as the dependent variable. The vari ables hypothesized to be related to each type of participation were entered as the independent vari ables in both analyses. The results of the two regres sion analyses appear in Table 5.

There was a significant positive relationship bet ween competition and both consultative $(\beta=0.09$, $p<0.001)$ and delegative participation $(\beta=0.14$, $p<0.001$ ), providing total support for Hypothesis 1. Sector also showed the expected relationship with both consultative $(\beta=0.14, p<0.001)$ and delega tive participation $(\beta=0.12, p<0.001)$; that is, 
Table 4

Means, standard deviations and correlations among study variables

\begin{tabular}{|c|c|c|c|c|c|c|c|c|c|c|c|}
\hline Variable & 1 & 2 & 3 & 4 & 5 & 6 & 7 & 8 & 9 & 10 & 11 \\
\hline 2. Delegation & 0.36 & & & & & & & & & & \\
\hline 4. Percentage of employees unionized & -0.04 & -0.05 & 0.11 & & & & & & & & \\
\hline 5. Competition & 0.10 & 0.03 & -0.34 & -0.03 & & & & & & & \\
\hline 6. Sector & 0.10 & 0.11 & 0.20 & -0.10 & -0.42 & & & & & & \\
\hline 8. Service strategy & 0.09 & 0.05 & 0.00 & -0.03 & 0.01 & 0.10 & 0.23 & & & & \\
\hline 9. Indirect participation & 0.13 & 0.01 & 0.11 & 0.31 & 0.00 & -0.07 & 0.04 & -0.01 & & & \\
\hline 10. Organizational size & 0.13 & -0.01 & 0.03 & 0.08 & 0.15 & -0.13 & 0.04 & 0.04 & 0.26 & & \\
\hline 11. Cost leadership strategy & -0.04 & -0.04 & -0.29 & -0.07 & 0.31 & -0.20 & 0.06 & 0.06 & -0.01 & 0.09 & \\
\hline Mean & 2.40 & 3.62 & 1.08 & 6.41 & 2.85 & 1.57 & 2.88 & 2.78 & 0.73 & 0.79 & 2.66 \\
\hline
\end{tabular}

Correlations greater than 0.029 are significant at the 0.05 level. Correlations greater than 0.035 are significant at the 0.01 level.

companies in the service sector adopted significantly higher levels of both types of participation than com panies in the manufacturing sector, as predicted by Hypothesis 2.

Three of the four hypotheses regarding differentia tion strategies, Hypotheses 3 and 4, were supported.
Organizations following a differentiation strategy based on quality adopted significantly higher levels of both consultative $(\beta=0.10, p<0.001)$ and dele gative participation $(\beta=0.09, p<0.001)$. Companies following a differentiation strategy based on service also had significantly higher levels of consultative

Table 5

Linear regression on consultative and delegative participation

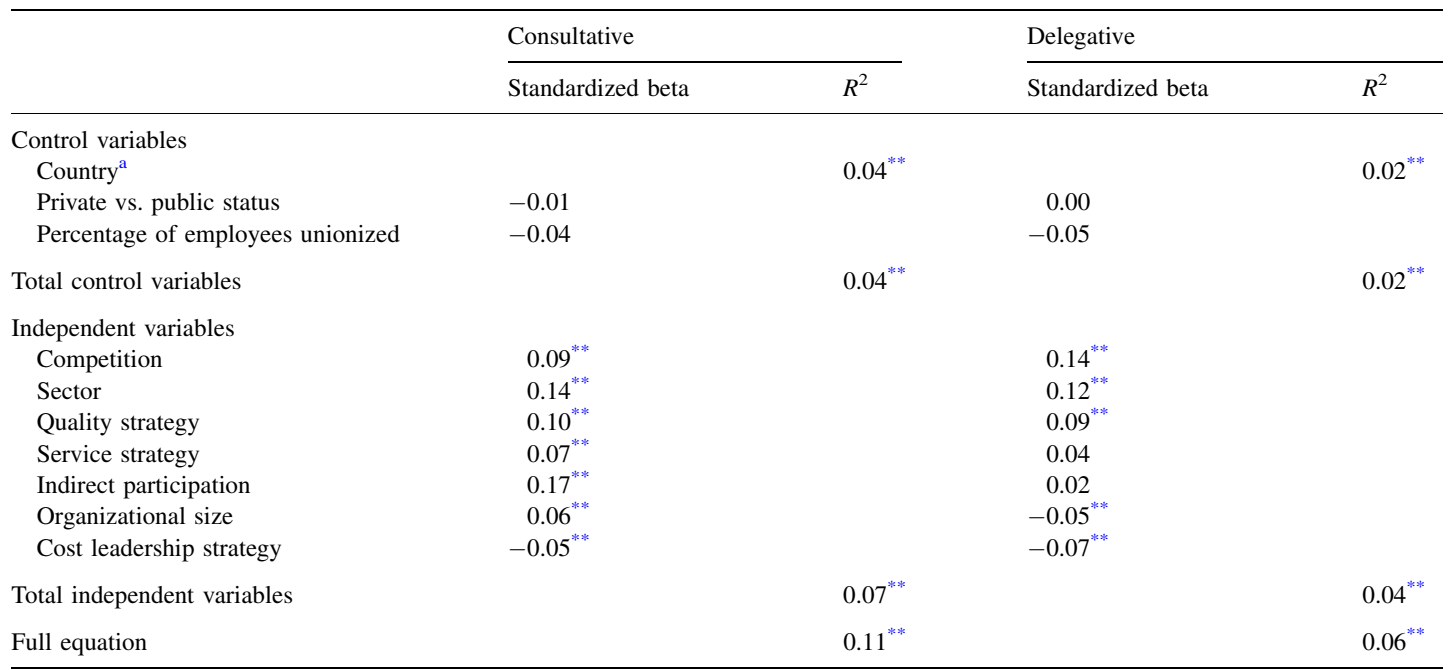

\footnotetext{
${ }^{\mathrm{a}}$ Based on nine dummy-coded variables.
}

*** $p<0.001$. 
participation $(\beta=0.07, p<0.001)$, however, there was not a significant relationship between the pursuit of a differentiation strategy based on service and delegative participation.

Finally, a significant positive relationship was found between level of indirect participation and consulta tive participation ( $\beta=0.17, p<0.001$ ), however, no relationship was found between amount of indirect participation and delegative participation, thus provid ing partial support for Hypothesis 5.

As far as the specific hypotheses regarding the use of different types of participation, consistent with Hypothesis 6, organizational size was positively rela ted to consultative participation $(\beta=0.06, p<0.001)$ and negatively related to delegative participation ( $\beta=-0.05, p<0.01)$. Finally, contrary to Hypoth esis 7, consultative participation was negatively related to a cost leadership strategy $(\beta=-0.05$, $p<0.001)$. However, the relationship between a cost leadership strategy and delegative participation was also negative $(\beta=-0.07, p<0.01)$, as expected. Therefore, Hypothesis 7 received only partial support.

\section{Discussion}

Eleven out of fourteen hypothesized relationships were supported. Level of competition was related to the amount of both types of employee participation. Most researchers agree that today's more competitive environment is one of the major causes of the increase in the use of participative management practices. This was clearly supported by our results, which showed a highly significant positive relationship between com petition and employee involvement.

Sector also influenced the use of participative man agement practices. Organizations in the service sector reported significantly higher levels of employee par ticipation than did organizations in the manufacturing sector. This could be due to the fact that these orga nizations recognize the benefits of having satisfied employees providing service to their customers (Bowen \& Lawler, 1995; Schneider \& Bowen, 1995). It may also be due to the fact that employees that are in direct contact with the customer are more aware of their needs and, therefore, have valuable information regarding how to better serve the client. Thus, organizations will be able to improve their customer service if the employees are involved in the decision making process. So, the predictions of both the affective and the cognitive models of parti cipation may explain these findings.

Level of participation, both consultative and dele gative, was significantly higher in organizations pur suing a differentiation strategy based on quality than in organizations not competing on the basis of quality. And amount of consultation was significantly higher in organizations pursuing a differentiation strategy based on service. Curiously, though, the pursuit of a strategy based on service was not related to amount of delegative participation. This finding is even more puzzling given the previous result, that organizations in the service sector had significantly higher levels of both forms of participation. It was expected that both types of differentiation strategies would be positively related to amount of participation. A concern for quality and service should heighten an organization's desire for having satisfied and involved employees for the reasons mentioned above. Further research is needed to explore the lack of a relationship between a service orientation and delegative participation.

Interestingly, amount of indirect participation was positively related to consultative participation, how ever, there was no relationship at all between indirect participation and delegative participation. Clearly indirect participation is closer in nature to consultative participation than to delegative participation. It appears then that regulation concerning indirect par ticipation may have a spillover effect on the use of consultation, however, it does not appear to encourage the use of more extreme forms of participation in decision making. The findings regarding the influence of indirect participation are especially interesting given that it has a significant influence on consultative participation over and above the effect that country has on this form of participation. Indirect participa tion was expected to be strongly influenced by national systems of labor regulation and, in fact, an ANOVA reveals significant differences in levels of indirect participation among countries $(F=30.88$, $p<0.001)$. And yet, indirect participation has a sig nificant impact on consultative participation even after taking into account the country effect.

This spillover effect may be explained by the results of a study by Gill and Krieger (2000) where they discovered that employee representatives in Europe 
play an active role in introducing direct participation into the workplace. They found that the initiative to introduce direct participation is usually taken by the managers. However, once a company has decided to introduce participation, employee representatives actively try to ensure the greatest range of participa tion possible. It may also be that once indirect parti cipation has been introduced into the workplace, employee representatives actively encourage their managers to widen the participation initiatives to include direct participation in the form of consulta tion.

Organizational size was the first factor hypothe sized to affect the two forms of participation differ entially. The results supported the expectation that organizational size would be positively related to consultative participation and negatively related to delegative participation. It does then appear that con sultation is a fairly easy management practice that large organizations can use to increase employee satisfaction or to increase information flows, however, it is likely that the complicity of delegative participa tion prevents it from being widely used in larger organizations.

The second factor predicted to have a different impact on the two forms of participation was the pursuit of a cost leadership strategy. While these organizations had significantly lower levels of dele gative participation, as expected, they did not adopt significantly higher levels of consultative participa tion. In fact, organizations pursuing a cost leadership strategy were characterized by significantly lower levels of consultation. Again, the argument that dele gative participation is likely to be perceived by these organizations as more costly would explain why it is used less in organizations pursuing cost leadership strategies. However, it appears that when cost is a priority, organizations are less willing to invest time in any type of participative management practices. These findings fail to support the argument that participation may be used in order to compensate employees for lower wages. That is, the prediction by the affective models that participation be used to increase levels of satisfaction does not seem to be supported here.

Finally, only one of the control variables, country, was positively related to both delegative and consul tative participation. ANOVAs contrasting levels of both forms of participation among the different coun
Table 6

Average consultative and delegative participation by country

\begin{tabular}{lll}
\hline Country & Consultative & Delegative \\
\hline Denmark & 2.44 & 3.70 \\
France & 2.61 & 3.72 \\
Germany & 2.16 & 4.15 \\
Ireland & 2.21 & 4.30 \\
Italy & 2.11 & 2.76 \\
The Netherlands & 2.88 & 4.51 \\
Portugal & 2.01 & 2.83 \\
Spain & 2.09 & 2.09 \\
Sweden & 2.33 & 4.37 \\
United Kingdom & 2.84 & 3.65 \\
\hline
\end{tabular}

tries reveal significant country differences for both consultative $(F=21.48, p<0.001)$ and delegative participation $(F=20.27, p<0.001)$. An examination of the means of consultative and delegative participa tion per country (Table 6) shows that The Netherlands has the highest level of both consultative and delega tive participation and that Portugal, Spain, and Italy are the lowest ranked countries for both forms of participation.

The fact that the "Mediterranean" countries have lower levels of participation is most likely influenced by their cultural differences with respect to the other countries. For instance, in these countries status dif ferences are quite important and there tends to be a lower tolerance for ambiguity (Hofstede, 1991; Schwartz \& Sagiv, 1995; Triandis, 1989). Participative management styles are less likely to be used in hierarchical cultures, where it is assumed that deci sions should be made by managers. Likewise, indivi duals in high uncertainty avoidance cultures feel comfortable in highly structured environments and tend to want to avoid conflict. Since participation leads to ever increasing demands to cope with uncer tainties and the potential of manifest conflict, these countries would also be expected to have lower levels of employee participation.

\section{Conclusion}

This study makes a number of contributions to the employee participation literature. First, it presents several hypotheses regarding the determinants of employee participation, as opposed to the more typical 
focus on the outcomes of employee participation. Second, it contrasts these hypotheses using data from over 5,000 organizations across 10 European coun tries, thus adding to the scant number of empirical studies that have explored the factors that influence amount of employee involvement.

A third contribution of this study is that it distin guishes among factors that affect levels of participa tion in general and those which affect two specific forms of participation differentially, namely consulta tive and delegative participation. In doing so, it fol lows the suggestions of Cotton et al. (1988) and Black and Gregersen (1997) that participation should be studied as a multidimensional construct. Although most factors were related to amount of participation in general, one was found to have a differential relationship with participation according to the form participation it takes. Organizational size was posi tively related to consultative participation, yet nega tively related to delegative participation. Also, the pursuit of a service strategy and level of indirect participation were found to be positively related to consultative participation, yet neither was related to delegative participation. These findings demonstrate the importance of measuring different types of parti cipation in order to be able to discover possible differences such as this.

A few final issues that merit mention are the fact that the EPOC survey only assessed direct forms of participation, thus the factors that influence the use of other forms of indirect participation could not be tested here. Also, the response rates for some of the countries were low. Notably, the rates for France, Italy and Spain were all below 15\%. These low response rates could affect our results in two possible ways. First, the estimates of levels of participation in these countries may be biased. If so, we expect the bias to be positive for the following reason. Research shows that survey response rates are lower for issues that are not salient or of interest to potential respondents (Roth \& Bevier, 1998). Thus, the firms that are less likely to respond are those that have not considered the possi bility of introducing participation. On the contrary, the firms that are more likely to respond are those that do use participation or have at least considered the possibility of introducing participation. As a conse quence, we expect the levels of employee participation to be greater among respondents than among non respondents. If this is so, the EPOC survey results would overestimate levels of participation, especially in the countries with the lowest response rates. Coun tries such as Italy or Spain, which already have low levels of participation according to EPOC, would have even lower levels of participation if one corrected for this bias.

A second possibility is that low response rates bias our estimates of the determinants of participation. This problem would be more important than the first one, because the focus of this study is on the factors that influence direct participation. However, we do not expect our findings regarding the determinants of participation to be strongly affected by the low response rate in some countries. If non respondents are, as we expect, firms with little interest in participa tion, than their potential responses would not be very informative about the determinants of participation. Ideally, the respondents should be firms that have at least considered the possibility of introducing direct participation.

A final caveat is to remind the reader that the data for this study was obtained using a cross sectional research design. This type of design can be proble matic in testing for causality due to the fact that all of the variables are measured at the same time. However, the nature of the variables in this study makes causal claims less problematic. That is, we feel it is unlikely that factors such as sector, strategy, organizational size, or competition are caused by participation. It may be argued that direct participation determines indirect participation, however, since indirect partici pation is often regulated, it is more likely that the causal direction goes from indirect to direct participa tion, as well.

In summary, the current study provides empirical evidence regarding the factors that influence amount and type of direct employee participation. The factors that were shown to have the strongest impact on general levels of employee involvement were: com petition, sector, and both the pursuit of a differentia tion strategy based on quality and a cost leadership strategy. All of these, except for the pursuit of a cost leadership strategy, affected employee participation positively. Indirect participation and the pursuit of a differentiation strategy based on service were both positively related to consultative participation but had no relationship with delegative participation. 


\section{Acknowledgments}

This research was funded in part by a grant (SEC2000-0395) from the Spanish Ministry of Science and Technology. We would like to thank Ulrich Pekruhl and the European Foundation for the Improvement of Living and Working Conditions for access to the EPOC survey results.

\section{References}

Aghion, P., \& Tirole, J. (1997). Formal and real authority in organizations. Journal of Political Economy, 105(1): 129.

Anthony, W. P. (1978). Participative management. Reading, MA: Addison Wesley.

Anthony, W. P., Perrewe, P. L., \& Kacmar, K. M. (1993). Strategic human resource management. Fort Worth, TX: The Dryden Press.

Beatty, J. R. (1991). Total quality management and the human resources professional. Perspectives in Total Compensation, 3: 16.

Black, J. S., \& Gregersen, H. B. (1997). Participative decision making: An integration of multiple dimensions. Human Relations, 50(7): 859878 .

Blake, R. R., \& Mouton, J. S. (1964). The managerial grid. Houston: Gulf.

Bowen, D. E., \& Lawler, E. E. (1995, Summer). Empowering service employees. Sloan Management Review: 7384.

Boyacigiller, N., \& Adler, N. J. (1991). The parochial dinosaur: Organizational science in a global context. Academy of Management Review, 16(2): 262290.

Child, J. (1981). Culture, contingency and capitalism in the cross national study of organizations. In L. L. Cummings \& B. M. Shaw (Eds.), Research in organizational behavior (pp. 303 356). Greenwich, CT: JAI Press.

Cotton, J. L. (1993). Employee involvement. Newbury Park, CA: Sage.

Cotton, J. L., Vollrath, D. A., Froggatt, K. L., Lengnick Hall, M. L., \& Jennings, K. R. (1988). Employee participation: Diverse forms and different outcomes. Academy of Management Review, 13: 822.

Deming, W. E. (1986). Out of crisis. Cambridge, MA: MIT Center for Advanced Engineering Study.

Doucouliagos, C. (1995). Worker participation and productivity in labor managed and participatory capitalist firms: A meta analysis. Industrial and Labor Relations Review, 49(1): 5877.

EPOC. (1997). New forms of work organisation: Can Europe realise its potential? Dublin, Ireland: European Foundation for the Improvement of Living and Working Conditions.
Frost, C. H., Wakely, J. H., \& Ruh, R. A. (1974). The Scanlon plan for organizational development: Identity, participation, and equity. East Lansing: Michigan State University Press.

Geary, J., \& Sisson, K. (1994). Conceptualising direct participation in organizational change. Luxembourg: The EPOC Project.

Gill, C., \& Krieger, H. (2000). Recent survey evidence in participation in Europe: Towards a European model? European Journal of Industrial Relations, 6(1): 109132.

Heller, F., Pusic, E., Strauss, G., \& Wilpert, B. (1998). Organiza tional participation: Myth and reality. Oxford: Oxford University Press.

Hofstede, G. (1991). Cultures and organizations: Software of the minds. London: McGraw Hill.

Huselid, M. A. (1995). The impact of human resource management practices on turnover, productivity, and corporate financial performance. Academy of Management Journal, 38(3): 635 672.

Hyman, J., \& Mason, B. (1995). Managing employee involvement and participation. London: Sage.

Jackson, S. E., \& Schuler, R. S. (1995). Understanding human resources management in the context of organizations and their environments. Annual Review of Psychology, 46: 237264.

Knudsen, H. (1995). Employee participation in Europe. London: Sage.

Lawler, E. E., Mohrman, S. A., \& Ledford, G. E. (1995). Creating high performance organizations. San Francisco: Jossey Bass.

Likert, R. L. (1967). The human organization. New York: McGraw Hill.

Markey, R., \& Monat, J. (1998). Innovation and employee participation through works councils: International case studies. Aldershot, England: Ashgate Publishing.

Mayo, E. (1933). The human problems of an industrial civilization. New York: Macmillan.

Miller, K. I., \& Monge, P. R. (1986). Participation, satisfaction and productivity: A meta analytic review. Academy of Management Journal, 29(4): 727753.

Pfeffer, J. (1994). Competitive advantage through people. Boston: Harvard Business School Press.

Porter, M. E. (1980). Competitive strategy. New York: Free Press.

Roth, P. L., \& Bevier, C. A. (1998). Response rate in HRM/OB survey research: Norms and correlates, 1990 1994. Journal of Management, 24(1): 97117.

Schneider, B., \& Bowen, D. E. (1995). Winning the service game. Boston: Harvard Business School Press.

Schwartz, S., \& Sagiv, L. (1995). Identifying culture specifics in the content and structure of values. Journal of Cross Cultural Psychology, 26(1): 92116.

Triandis, H. C. (1989). The self and social behavior in differing cultural contexts. Psychological Review, 96: 506520.

Wagner, J. A. (1994). Participation's effects on performance and satisfaction: A reconsideration of research evidence. Academy of Management Review, 19(2): 312330. 